Canadian Journal of Fisheries and Aquatic Sciences

Canadian

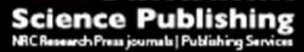

Journal canadien des sciences halieutiques et aquatiques

\title{
Dynamic trophic linkages in a large estuarine system - support for supply-driven dietary changes using delta generalized additive mixed models
}

\begin{tabular}{|r|l|}
\hline Journal: & Canadian Journal of Fisheries and Aquatic Sciences \\
\hline Manuscript ID & cjfas-2014-0441.R1 \\
\hline Manuscript Type: & Article \\
\hline Date Submitted by the Author: & 21 -Apr-2015 \\
\hline Complete List of Authors: & $\begin{array}{l}\text { Buchheister, Andre; University of Maryland Center for Environmental } \\
\text { Science, Chesapeake Biological Laboratory } \\
\text { Latour, Robert; Virginia Institute of Marine Science, Fisheries Science }\end{array}$ \\
\hline Keyword: & $\begin{array}{l}\text { PREDATOR-PREY INTERACTION < General, DIET < General, STATISTICAL } \\
\text { ANALYSIS < General, ENVIRONMENTAL EFFECTS < General, ESTUARIES < } \\
\text { Environment/Habitat }\end{array}$ \\
\hline
\end{tabular}


1 Dynamic trophic linkages in a large estuarine system - support for supply-

2 driven dietary changes using delta generalized additive mixed models

3

4 Andre Buchheister ${ }^{\mathrm{a},{ }^{*}}$ and Robert J. Latour ${ }^{\mathrm{a}}$

5

$6 \quad{ }^{a}$ Virginia Institute of Marine Science, College of William \& Mary, P.O. Box 1346, Gloucester

7 Point, VA 23062, USA.

8

$9 \quad$ Submitted to Canadian Journal of Fisheries and Aquatic Sciences

10

11 Corresponding author: Andre Buchheister (e-mail: andrebuc@umces.edu; Tel.: +1-410-326-

12 7396; fax: +1-410-326-7264)

13 *Present address: Chesapeake Biological Laboratory, University of Maryland Center for

14 Environmental Science, P.O. Box 38, Solomons, MD 20688, USA 
15 Abstract: Trophic dynamics within aquatic systems are a predominant regulator of fish

16 production and an important consideration for implementing ecosystem approaches to fisheries

17 management. We analyzed ten years of fish diet data from Chesapeake Bay, USA to 1) evaluate

18 the effects of environmental variables on trophic interactions of 12 common predatory fishes, 2)

19 infer dynamics of four key prey groups (mysids, bay anchovy, bivalves, and polychaetes), and 3)

20 evaluate whether interannual dietary trends were coherent among predators and regulated by

21 prey availability. Based on delta generalized additive mixed models (delta-GAMM), predator

22 length was the most important covariate in modeling prey consumption. When significant,

23 latitude, temperature, and depth effects were largely similar across predators for a given prey.

24 Annual patterns of mysid and bivalve consumption each showed a single, dramatic peak shared

25 by multiple predators with varied feeding preferences and distributional characteristics, but

26 annual trends were not correlated with available survey-based measures of prey availability

27 likely due to methodological differences. Overall, the coherence in consumption patterns across

28 predators was consistent with supply-driven dynamics controlled by regional and annual changes

29 in prey availability. Also, the novel application of delta-GAMM to fish diet data was useful in

30 characterizing the dynamics of poorly sampled prey groups and the trophic interactions for

31 ubiquitous species from the Northwest Atlantic Ocean.

32

33 Keywords: trophic ecology, diet analysis, fish stomach contents, statistical methods,

34 environmental effects 


\section{Introduction}

Trophic dynamics have been described as one of the three principal drivers of fisheries

38 production (Link 2010; Gaichas et al. 2012). Trophic dynamics control not only the direct

39 consequences of predation (e.g., mortality, survival, growth, changes in population biomass, and

40 modified size structure) but also a myriad of indirect ecological effects (e.g., changes in

41 behavior, distribution, habitat utilization, foraging, and competition), all of which are critical to

42 governing the structure and function of aquatic food webs (Carpenter et al. 1985; Whipple et al.

43 2000). Consequently, understanding the factors regulating predator-prey interactions is an

44 important consideration in applying a more holistic, ecosystem-based approach to managing

45 fisheries resources (Link 2002; Latour et al. 2003). One of the challenges to advancing

46 knowledge on predator-prey interactions is to continue moving beyond basic diet descriptions by

47 evaluating the factors regulating the dynamics of food web linkages, including how

48 environmental conditions and prey availability alter foraging patterns (Link 2002; Hunsicker et

49 al. 2011).

Chesapeake Bay is one model system where researchers and managers are interested in

51 understanding how the environment and prey availability regulate dynamic predator-prey

52 interactions, in part to facilitate ecosystem-based fisheries management (EBFM) efforts (Houde

53 2006; Christensen et al. 2009). Chesapeake Bay is the largest juvenile nursery and estuarine

54 foraging ground in the northwest Atlantic Ocean, supporting many fish stocks and their

55 commercial and recreational fisheries (Able and Fahay 2010). Consequently, variability in

56 predator-prey interactions in the bay can influence recruitment, growth, mortality, and

57 production of many valuable fishes. Mysids, bay anchovy, bivalves, and polychaetes, in

58 particular, are four key prey groups in Chesapeake Bay that have a proportionately large 
59 influence on the bay's diverse fish assemblage (Buchheister and Latour 2015). However, there is

60 limited information on the basic biological and ecological characteristics of these prey groups

61 (particularly mysids) and their trophic interactions with predators at larger spatiotemporal scales

62 in estuaries. The availability of extensive fish diet data in Chesapeake Bay (Buchheister and

63 Latour 2015) provides a unique opportunity for obtaining some of this information.

Fishes are biological samplers of their environment and thus predator diets can be used as

65 indicators of prey dynamics and availability, particularly for cryptic or poorly sampled prey

66 groups. Generally, prey consumption rate for an un-satiated predator increases with the prey's

67 density (Holling 1959), and many fishes are generalist or opportunistic feeders whose foraging is

68 strongly regulated by prey encounter rates (Gerking 1994; Juanes 1994). These density-

69 dependent foraging characteristics have allowed scientists to use predator diets to estimate prey

70 distributions (Fahrig et al. 1993; Link 2004), derive annual indices of relative prey abundance

71 (Link 2004; Mills et al. 2007), and corroborate long term changes in prey availability (Dwyer et

72 al. 2010; Pálsson and Björnsson 2011).

73 Making inferences on prey availability from predator diets can be biased by

74 environmental conditions, prey selectivity, and foraging efficiency (Eggers 1977; Juanes 1994).

75 These potential biases are analogous to difficulties faced in deriving indices of relative

76 abundance from traditional fish survey gears, and two approaches are useful in that context.

77 First, statistical models can standardize indices by partitioning variability and accounting for the

78 effects of different covariates (Maunder and Punt 2004; Kimura and Somerton 2006) and second,

79 multiple gear types with different sampling properties can be used synoptically to derive more

80 robust estimates of a desired response variable. Extension of this reasoning to trophic studies

81 suggests that indices of prey consumption would be more representative of prey availability once 
82 standardized for heterogeneous environmental conditions that introduce variability into predator-

83 prey interactions, and also that synchronous patterns across multiple predators would strengthen

84 the robustness of conclusions for individual prey. An added benefit of this prey-centric analytical

85 approach is that when limited biological data exist for the prey, the effects of modeled covariates

86 can be used to draw inference on prey distribution, availability, and dynamics.

87 In this study, we evaluate the trophic interactions among several dominant fishes and key

88 prey groups in Chesapeake Bay. We used diet composition data from an extensive, multi-

89 seasonal bottom trawl survey of Chesapeake Bay fishes to address three objectives: 1) evaluate

90 the influence of predator length, spatiotemporal factors, and environmental drivers on prey

91 consumption by 12 common Chesapeake Bay predators, 2) compare diet patterns across

92 predators to infer basic dynamics of four key prey groups, and 3) evaluate whether interannual

93 consumption trends were coherent among predators and correlated with annual prey abundance.

94 We detail the trophic dynamics for several predators and prey groups that occur ubiquitously in

95 estuarine and nearshore coastal waters throughout the Atlantic, contributing to ongoing efforts in

96 ecosystem modeling and EBFM in Chesapeake Bay and the continental shelf (Latour et al. 2003;

97 Houde 2006; Link et al. 2011). From a methodological perspective, this work is a novel

98 application of delta generalized additive mixed models to draw ecological inference from dietary

99 data while addressing several statistical problems common in trophic studies.

100

101 Methods

102 Field and laboratory methods

103 Data were obtained from the Chesapeake Bay Multispecies Monitoring and Assessment

104 Program (ChesMMAP), operated by the Virginia Institute of Marine Science. Since 2002, this

105 bottom trawl survey has sampled the Chesapeake Bay mainstem using a random-stratified design 
106 with stations stratified by depth and latitude (Fig. 1). Typically, five cruises were conducted per

107 year (bimonthly from March to November), with approximately 80 stations sampled per cruise.

108 Data on latitude, longitude, water depth, bottom temperature, salinity, and dissolved oxygen

109 were collected at each station. After catches were sorted, species with broad length distributions

110 or discrete length groups were further sorted into 2-4 size classes, random individual subsamples

111 from the species-size-class groups were processed for weight and length (fork length for teleosts;

112 disc width for batoids), and stomachs were removed for diet analysis. If stomachs were visually

113 confirmed to be empty in the field, additional specimens (when available) were processed to

114 obtain 3-5 nonempty stomachs per species and size class. In the laboratory, contents from

115 preserved stomachs were sorted by trained technicians, identified to the lowest possible taxon

116 using dissection microscopes, and prey categories weighed to the nearest $0.001 \mathrm{~g}$.

117 We focused on four prey groups for this study: 1) mysid shrimp (primarily Neomysis

118 americana), 2) bay anchovy (Anchoa mitchilli, with very minor contribution of Anchoa

119 hepsetus), 3) bivalves (dominant species included Ensis directus, Gemma gemma, Macoma spp.,

120 Mercenaria mercenaria, Mya arenaria, and Tagelus plebeius), and 4) polychaete worms

121 (including families Capitellidae, Chaetopteridae, Glyceridae, Maldanidae, Nereidae,

122 Pectinariidae, Terebellidae). These four prey groups were chosen because they represent

123 relatively unique functional morphologies and are largely responsible for differentiating among

124 fish trophic guilds within Chesapeake Bay (Buchheister and Latour 2015). The bivalve and

125 polychaete groups were defined at a coarse taxonomic level because 1) prey were often not

126 identifiable to greater taxonomic resolution due to digestion, 2) sample sizes were relatively low

127 for predators with identifiable bivalve and polychaete taxa. Predators for each of the four prey

128 groups were restricted to species with $>15 \%$ frequency occurrence and a minimum sample size 
129 of 140 stomachs that contained the prey group. These two criteria excluded predators that rarely

130 consumed a given prey group and omitted predators with low sample sizes. These restrictions

131 yielded a total of 12 predator species with a total of 29,350 analyzed stomachs (Table 1).

132 Depending on the species, $9-42 \%$ of sampled fish stomachs were empty (27\% overall). Each

133 predator-prey combination was represented by at least 146 fish and up to 2,301 fish that

134 contained the prey of interest. Summaries of general diet compositions (\% weight) for the

135 selected predators were calculated using a cluster sampling estimator by pooling across all

136 available non-empty stomachs (see Buchheister and Latour 2015 for equations).

\section{Delta generalized additive mixed models}

Statistical analysis of stomach content data is often complicated by three statistical issues.

140 First, diet data often suffer from an overabundance of zero values that does not conform to

141 standard statistical distributions. Second, samples of fish stomachs often violate the assumption

142 of independence when multiple individuals are captured at the same location or when individuals

143 are sampled repeatedly through time (e.g., in experimental studies) because samples will be auto-

144 correlated in time and space (Hurlbert 1984; Bogstad et al. 1995; Millar and Anderson 2004).

145 Third, the effects of covariates (e.g., temperature, predator size) on diets are often non-linear.

146 To account for these three complications, we applied delta generalized additive mixed

147 models (delta-GAMM) to model the consumption of a prey group by an individual predator

148 species. This approach built on the methods promoted by Stefánsson and Pálsson (1997) by

149 accounting for the non-independence of the diet samples using random effects. Delta-GAMM

150 combines statistical aspects of delta models (also known as two-part, hurdle, or zero-altered

151 models), generalized additive models (GAM), and mixed effects models. The use of a GAM 
152 allows for the effect of covariates to take flexible, nonlinear forms that are dictated by a

153 smoothing function (Wood 2006), but GAMs rely on the assumptions of independent and

154 identically distributed errors with constant variance. To account for the violation of the

155 independence assumption caused by the intra-station (i.e., intra-haul) correlation and by the

156 nested nature of the sampling design, we included station as a random effect in a mixed model

157 (Wood 2006; Zuur et al. 2009). To deal with the high frequency of zero values, the delta

158 approach was used to model the data in two parts: first, the presence-absence of a given prey in

159 the stomachs of a predator was modeled (termed the "binomial" model henceforth); and second,

160 the weight of prey consumed was modeled, provided that the prey occurred in the stomach

161 (termed the "positive" model henceforth). All models were fitted to individual predator-prey

162 combinations.

163 The binomial models estimated the probability that a stomach contains the prey of

164 interest, analogous to modeling the frequency of occurrence of a given prey. The first, binomial

165 stage of the delta-GAMM modeled presence absence data $\left(a_{i j}\right)$ as $a_{i j} \sim \operatorname{binomial}\left(1, p_{i j}\right)$ with

$166 \quad(1) \quad \operatorname{logit}\left(p_{i j}\right)=\alpha+\beta\left(Y R_{i}\right)+\mathrm{f}_{1}\left(L_{i}\right)+\mathrm{f}_{2}\left(L A_{i}\right)+\mathrm{f}_{3}\left(T_{i}\right)+\mathrm{f}_{4}\left(D_{i}\right)+b_{j}$

167 where $\operatorname{logit}\left(p_{i j}\right)=\log \left(p_{i j} /\left(1-p_{i j}\right)\right), p_{i j}$ is the expected probability that fish $i$ from station $j$ contains

168 the prey of interest, $\alpha$ is the overall intercept, $\beta$ is a vector of parametric effects for the

169 categorical year $(Y R)$ factor, and $\mathrm{f}_{1-4}$ are smooth functions for each covariate (Wood 2006; Zuur

170 et al. 2009). The continuous covariates included predator length $(L)$ in $\mathrm{mm}$, latitude $(L A)$ in

171 decimal degrees, water temperature $(T)$ in ${ }^{\circ} \mathrm{C}$, and water depth $(D)$ in $\mathrm{m}$. The $b_{j}$ term is the

172 independent and identically distributed random station effect which is assumed to be normally

173 distributed with mean of zero and variance of $\sigma_{b}^{2}$. Available data on longitude, salinity, dissolved

174 oxygen, and month were not included in the model to avoid convergence issues resulting from 
175 overly complex models and to avoid slight collinearity among some variables. Models with

176 interactions among variables (including variable coefficient GAMM; Wood 2006) were not

177 formally evaluated because 1) graphical analyses did not indicate the presence of strong

178 interactions (Zuur et al. 2010), 2) they would decrease sample sizes and precision of covariate

179 effects, and 3) they often prohibited model convergence based on preliminary analyses.

180 The second, positive component of the delta-GAMM excludes all zeros and models the 181 quantity of prey consumed, relying on an appropriate data distribution. We chose to model the 182 biomass of prey consumed because this measure is more meaningful than prey counts in

183 dictating the transfer of energy through food webs (e.g., Pauly et al. 2000). Also, prey abundance 184 could not always be quantified due to digestion. We did not back-calculate the fresh weights of 185 consumed prey, but instead assumed that the modeled covariate effects on the measured weights 186 would be representative of the processes regulating consumption of fresh prey. Prey biomass was 187 not modeled with a gamma distribution as done by Stefánsson and Pálsson (1997) because this 188 distribution resulted in convergence issues for most predator-prey combinations in the GAMMs.

189 Instead, we used a log-transformation of the biomass data in conjunction with a Gaussian

190 distribution to alleviate convergence issues and homogenize the originally heteroscedastic

191 residuals. The model for the second stage of the delta-GAMM, restricted to fish stomachs that 192 contained a given prey, was defined as:

193

$$
\log \left(\mu_{i j}\right)=\alpha+\beta\left(Y R_{i}\right)+\mathrm{f}_{1}\left(L_{i}\right)+\mathrm{f}_{2}\left(L A_{i}\right)+\mathrm{f}_{3}\left(T_{i}\right)+\mathrm{f}_{4}\left(D_{i}\right)+b_{j}+\varepsilon_{i j}
$$

194 where $\mu_{i j}$ is the expected mass (in g) of a prey group in the stomach of fish $i$ from station $j$ given 195 the random effect $b_{j}$, and $\varepsilon_{i j}$ is the residual error for each fish and station assumed to be normally 196 distributed with a mean of zero and variance of $\sigma_{\varepsilon}^{2}$ (Wood 2006; Zuur et al. 2009). Definitions

197 for all remaining components of the model are identical to those for equation 1. 
All GAMMs were fitted to data from each of the 22 predator-prey combinations (Table

199 1), and Akaike's Information Criterion (AIC) was used to select the optimal fixed effects

200 structure (Burnham and Anderson 2002). Models with all possible combinations of explanatory

201 variables were evaluated, with the exception that $Y R$ was retained in all iterations to evaluate

202 interannual consumption trends (objective 3). Partial effects plots for the best-fit models were

203 used to demonstrate the effect of each covariate on the response after accounting for all other

204 covariates in the model, and they were presented on the scale of the linear predictor (logit scale

205 for binomial model results; log scale for positive model results). Goodness-of-fit measures (e.g.,

206 percent of deviance explained or $\mathrm{R}^{2}$ ) are still being developed for mixed models (Nakagawa and

207 Schielzeth 2013) and there is no standard summary statistic for overall GAMM fit, so these

208 measures were not estimated. However, as a general proxy for overall goodness of fit, a fixed-

209 effects version of each model (without the random station effect) was fitted to estimate the

210 percent of deviance explained by the model. We fitted all statistical models with the gamm4

211 package (Wood 2012) in R 3.0.1 (R Core Team 2013).

212

\section{Annual trends in consumption}

214 A combined index of prey consumption for year $y\left(C_{y}\right)$ was obtained for each predator-

215 prey combination by multiplying predictions for the binomial and positive components of the

216 best-fit delta-GAMMs. The consumption index was calculated as $C_{y}=p_{y}{ }^{*} \mu_{y}$ where $p_{y}$ is the

217 expected probability that a predator from year $y$ consumed a given prey, and $\mu_{y}$ is the expected

218 mass of the prey in a predator's stomach in year $y$. Predictions were standardized for the other

219 covariates by holding them constant at the mean values observed for each predator species (e.g., 
220 see Table 1 for mean predator lengths). All $\mu_{y}$ values were bias-corrected for back transformation

221 from lognormal space (Sprugel 1983).

222 To evaluate the similarity in prey consumption patterns across predators and the influence

223 of prey availability, Pearson correlations (R) were calculated among predator estimates of logged

$224 C_{y}$ and indices of prey abundance. Logging of consumption indices was needed to normalize the

225 data distributions and to prevent biased correlations due to outlier values. Indices of annual

226 biomass for polychaetes and bivalves were calculated as geometric means (mean of

$227 \log (\mathrm{x}+0.001)$, where $\mathrm{x}=$ biomass density in $\left.\mathrm{g} \mathrm{m}^{-2}\right)$ using data from the Chesapeake Bay Benthic

228 Monitoring Program for the randomly selected stations surveyed within the bay mainstem

229 (Versar, Inc., www.baybenthos.versar.com). Bivalves from this dataset were restricted to the

230 most common species found in predator stomachs (Ensis directus, Gemma gemma, Macoma

231 spp., Mercenaria mercenaria, Mya arenaria, and Tagelus spp.), but only Macoma spp. and

232 Gemma gemma were regularly sampled (occurring in 49\% and 13\% of stations, respectively).

233 Annual abundance indices for bay anchovy were obtained from the Virginia Institute of Marine

234 Science Juvenile Fish and Blue Crab Trawl Survey (Tuckey and Fabrizio 2012). Data on patterns

235 of mysid annual abundance were not available from any existing Chesapeake Bay monitoring

236 program. Significance of Pearson correlations were determined from critical R values based on

237 Bonferroni-adjusted $\alpha$ values $\left(\alpha_{\text {adjusted }}=0.05 / n\right.$, where $n$ is the number of pairwise correlations

238 for a given prey group). Spot were omitted from correlation analysis due to lack of stomach

239 content data from 2002-2007. To facilitate visual comparison of annual consumption and prey

240 indices across predators, all $C_{y}$ values and prey indices were standardized to range from $0-1$.

241 These standardized $C_{y}$ values were calculated as $\left(C_{y}-C_{\min }\right) /\left(C_{\max }-C_{\min }\right)$, where $C_{\min }$ and $C_{\max }$

242 are the minimum and maximum values for $C_{y}$ across the time series. 


\section{Results}

246 The four prey groups of focus contributed substantially to predator diets. Collectively,

247 bay anchovy, mysids, bivalves, and polychaetes accounted for large fractions of the fish diets

248 (13-64\%), reinforcing the broad importance of these prey to the examined predators (Fig. 2).

249 Individual prey groups contributed as much as $41 \%$ to the overall diet of a predator, though these

250 dietary contributions can be greater for specific predator size classes (Buchheister and Latour $2512015)$.

252

\section{Generalized additive mixed modeling}

254 The best-fitting binomial and positive GAMMs included various combinations of the

255 explanatory variables, ranging from all variables to none of the variables (except $Y R$, which was

256 forced; Table 2). Generally, the binomial models were more complex than the positive models;

257 however, this may be partially attributed to lower samples sizes for positive models which may

258 have restricted the ability to detect significant covariate effects. Proxies for the deviance

259 explained by models varied among predator-prey combinations, ranging from 4.3-36.7\% (mean

$26014.1 \%$ ) for binomial models and 5.4-49.3\% (mean 19.6\%) for positive models. These goodness

261 of fit values are comparable to other dietary studies that employed additive models and reflect

262 the relatively large amount of variability inherent in diet composition data (Stefánsson and

263 Pálsson 1997; Santos et al. 2013).

264 Length and latitude were typically the two most important covariates in the models

265 (Table 2), indicating the importance of both size limitation and spatial dynamics in trophic 
266 interactions. Most binomial models of prey consumption included length and latitude as

267 significant covariates; best-fitting models that did not include length were typically for predators

268 with relatively smaller length ranges. Significance of depth and temperature varied by prey;

269 depth was not important for bivalves, and temperature was typically excluded from polychaete

270 models. For the positive models, predator length was again a consistently important covariate,

271 yet few models included latitude or temperature. Only two positive models revealed significant

272 effects of water depth.

273 Consumption of mysids by predators was strongly influenced by the modeled covariates.

274 Predator length produced the strongest effect on the probability of mysids being consumed, with

275 larger individuals far less likely to consume this small-bodied prey (Fig. 3). The prey biomass

276 consumed tended to increase across predators at smaller sizes prior to declining, with this

277 transition occurring between $\sim 150-300 \mathrm{~mm}$ (Fig. 3). Both the occurrence and the biomass

278 consumed indicated greater mysid availability at lower latitudes for the predators with the largest

279 sample sizes (Fig. 3). Temperature effects on mysid occurrence and biomass were inconsistent

280 across predators, preventing clear conclusions regarding the influence of temperature on mysid

281 dynamics. Mysid occurrences in stomachs were slightly greater at shallower depths, but weakfish

282 contradicted this pattern.

283 Bay anchovy consumption was strongly influenced by predator length (Fig. 4). The

284 parabolic shape for the binomial model indicates a strong peak in prey occurrence at sizes $\sim 175-$

$285300 \mathrm{~mm}$, with weakfish targeting bay anchovy at slightly smaller sizes than summer flounder and

286 striped bass. The mass of bay anchovy found in stomachs increased with predator size until

287 leveling off at sizes that corresponded to the peaks in bay anchovy occurrence (Fig. 4). A size

288 effect on biomass consumed was not detected for striped bass. Effects of latitude on the 
289 probability of bay anchovy consumption differed by predator, with striped bass opposing the

290 trend of greater bay anchovy occurrence at higher latitudes. Temperature effects varied by

291 predator, and again striped bass opposed the general trend detected for the other species.

292 Weakfish and summer flounder results indicated greater probability of bay anchovy consumption

293 at lower temperatures. Depth effects on occurrence were negligible, although there was some

294 evidence for increased bay anchovy occurrence in shallower water.

295 Consumption of bivalves by Chesapeake Bay predators was strongly influenced by

296 predator length and latitude (Fig. 5). Dietary occurrence of bivalves increased with length for

297 Atlantic croaker, white perch, and northern puffer, but appeared to reach an asymptote for

298 Atlantic croaker. The biomass consumed also increased steeply with predator size. When viewed

299 in unison, the latitude effects for all predators demonstrated a decreased occurrence of bivalves

300 in stomachs at mid-latitudes, with increases in both the lower and upper bays (Fig. 5). For

301 Atlantic croaker, the mass of consumed bivalves also supported this parabolic latitudinal trend in

302 prey availability. Water temperature had a positive effect on bivalve occurrence in fish stomachs

303 for three species, but only white perch showed a similar positive relationship when modeling

304 prey biomass. Depth was not a significant covariate for any of the bivalve GAMMs.

305 Patterns of polychaete consumption showed varied responses to covariates depending on

306 the predator. Dietary occurrence of polychaetes varied greatly by predator length depending on

307 the species, but tended to increase with size before decreasing at larger sizes (Fig. 6). The biggest

308 exception to this pattern was for kingfish for which occurrence decreased monotonically. The

309 biomass of consumed polychaetes increased with predator length at similar rates across

310 predators, with only striped bass showing a reliable indication of saturation at larger sizes (Fig.

311 6). Latitudinal effects on the probability of polychaete consumption tended to show an inverse 
312 pattern to bivalve occurrence by latitude (Figs. 5, 6). Polychaete occurrences were generally

313 greatest in mid-latitudes, but latitude did not have significant effects on biomass of consumed

314 polychaetes for the majority of modeled predators (Fig. 6). Temperature effects on polychaete

315 occurrence and biomass were largely negligible across the majority of predators (Fig. 6). Depth

316 effects on polychaete occurrence were inconclusive as a whole at shallow depths, but most fishes

317 indicated decreasing occurrence as depth increased beyond $\sim 10 \mathrm{~m}$ (Fig. 6).

\section{Annual trends in consumption indices}

Standardized indices of annual prey consumption varied through the time-series but

321 demonstrated some synchronous and coherent trends across predators. Generation of the annual

322 consumption index clarified the interpretation of the year effects from individual binomial and

323 positive GAMM models (Fig. S1). Five of seven predators (Atlantic croaker, northern searobin,

324 scup, summer flounder, weakfish) exhibited a distinct annual peak in consumption of mysids in

325 2003, with a magnitude dramatically greater than other years (Fig. 7). Correlations among annual

326 trends for these five species were strong and ranged from $0.56-0.90$, with 3 of 10 values being

327 significant $(\mathrm{R}>0.84$, Bonferroni-corrected $\mathrm{p}<0.05$; Table 3$)$. Only striped bass and spotted hake

328 did not conform to this pattern. Consumption of bay anchovy by summer flounder and striped

329 bass exhibited largely synchronous changes in directionality (Fig. 7) and were strongly

330 correlated $(\mathrm{R}=0.71)$, though not significantly. Although consumption indices were not correlated

331 with the bay anchovy index (Table 3), the highest consumption values for summer flounder and

332 weakfish (and second highest value for striped bass) were obtained in 2010 when the prey index

333 was at its highest. Bivalve consumption had a peak in 2008 that was shared by all predators (Fig.

334 7). Although some bivalve trends were strongly correlated with one another or with the prey 
335 index $(\mathrm{R}=0.69-0.74)$, non were significant (Table 3). Consumption indices of polychaetes were

336 highly variable among predators; however, the highest values occurred in the last five years of

337 the time series, and four of the seven predators (Atlantic croaker, scup, spot, and white perch)

338 consumed the greatest amount of polychaetes in 2010 (Fig. 7). None of the pairwise polychaete

339 correlations among predators and the prey index were signficant (Table 3).

\section{Discussion}

Biological, environmental, and spatiotemporal factors strongly regulated predatory

344 consumption of four key prey groups in Chesapeake Bay. Despite the notorious variability of

345 fish diet data generated from the complex processes that influence trophic dynamics (Gerking

346 1994; Wootton 1998), the use of an extensive data set, multiple opportunistic predators, and the

347 novel application of delta-GAMMs aided in illuminating more robust commonalities in feeding

348 patterns that appear to be linked to prey availability at both small and large scales. Predator

349 length and latitude were particularly important covariates influencing many predator-prey

350 interactions. Coherent annual peaks in mysid, bay anchovy, and bivalve consumption were

351 suggestive of episodic, annual pulses in prey productivity that may be mediated by bottom-up

352 processes. These dynamic changes in consumptive patterns have the potential to influence

353 regional and annual patterns in fish productivity (e.g., Buchheister et al. in review) and are thus

354 an important consideration in managing fisheries in a broader, ecosystem context (Link 2010). 


\section{Predator length as a strong determinant of diet}

Predator length was the most consistently important determinant of prey consumption,

358 supporting a vast literature that emphasizes the significance of body size in structuring trophic

359 interactions (e.g., Juanes 1994; Scharf et al. 2000; Kerr \& Dickie 2001). Among other things,

360 body size regulates the foraging process by controlling the physical constraints on the size and

361 types of prey that can be ingested, the speed and endurance of a predator, the relative success of

362 foraging attacks, and the visual limit for prey detection (Eggers 1977; Scharf et al. 2002). In this

363 study, the binomial GAMM effects for predator length provide information on the continuous

364 functional forms of relative prey occurrence in predators of varying sizes. The forms of these

365 size-based occurrence curves were either linear, asymptotic, or dome-shaped (which translate to

366 sigmoidal, asymptotic, and dome shapes when converted to the $0-1$ probability scale). The

367 sigmoidal decline in consumption of mysids supports their greater importance to juveniles and

368 smaller sized individuals (Mauchline 1980; Hostens and Mees 1999), while the sigmoidal or

369 asymptotic increase in bivalve consumption suggests this prey is a "terminal" prey for which

370 occurrence is greatest at the most advanced ages and sizes that were sampled (Buchheister and

371 Latour 2015). The dome shapes for bay anchovy and polychaetes identified these prey as being

372 transitional forage resources as predators grew (through the examined sizes), reaching

373 consumption optima at intermediate sizes. Generally, these bay anchovy optima corresponded

374 with significant shifts in diet composition based on discrete size-class cutoffs (Latour et al. 2008;

375 Buchheister and Latour 2015), and they also corresponded with published distributions of

376 predator-prey size ratios for summer flounder and weakfish (Scharf et al. 2000). The empirically-

377 derived occurrence curves may be useful in informing the parameterization of size-based 
378 components of prey suitability functions that are used in foraging or multispecies models

379 (Garrison et al. 2010).

$381 \quad$ Prey dynamics

Predator diets contributed to the basic understanding of mysid distribution and

383 abundance. Despite the importance of mysids in estuarine and marine food webs (Mauchline

384 1980, Jumars 2007), relatively little is known about basic mysid dynamics in Chesapeake Bay

385 and similar estuaries. Our diet analysis suggests mysid availability and presumably density was

386 highest at lower latitudes in the Chesapeake Bay’s polyhaline region near the mouth. In contrast,

387 densities of N. americana, the predominant mysid in local fish diets (Buchheister and Latour

388 2015), peaked at mesohaline salinities 50-90 km away from the mouth of Delaware Bay

389 (Hulburt 1957, Cronin et al. 1962). These trends are consistent with the hypothesis that coastal

390 waters act as the major source for estuarine mysid populations (Whitely 1948; Hulburt 1957;

391 Hopkins 1965), and they suggest that physical advection and distance from the coastal

392 population source may be more important than specific salinity regimes in dictating estuarine

393 mysid distributions in large estuaries like Chesapeake Bay. However, mysid consumption did

394 occur throughout the entire sampled area, likely supported by local estuarine reproduction that

395 can occur through their hypothesized 2-3 annual reproductive cycles (Hulburt 1957) and their

396 tolerance for a broad range of salinities (Mauchline 1980). Although mysid populations tend to

397 peak in summer months with warmer temperatures, mysids can be found throughout the year in

398 Mid-Atlantic estuaries (Hulburt 1957; Hopkins 1965). This seasonal ubiquity contributed to the

399 lack of consistent dietary occurrence trends with temperature, and supports the importance of

400 mysids as a food resource throughout the year to a variety of resident and seasonally migrating 
401 predators (Buchheister and Latour 2015). Analyses suggested greater mysid availability in 402 relatively shallower bay areas (4-15 m) based on the diets, contrary to trends in Delaware Bay 403 where Hulburt (1957) noted low mysid concentration in areas $<5.5 \mathrm{~m}$. However, his study 404 sampled during daylight hours in surface waters when mysids typically reside on the benthos 405 (Herman 1963).

406 Bay anchovy are the most abundant fish in the Chesapeake Bay and they contribute 407 substantially to the production of commercially and recreationally important piscivorous species 408 like striped bass, summer flounder, weakfish, and bluefish (Baird and Ulanowicz 1989; Houde 409 and Zastrow 1991). For many piscivores, bay anchovy acts as a key forage species that bridges 410 the transition from small zooplanktonic and benthic prey to larger forage fishes (Buchheister and 411 Latour 2015, this study). The conflicting latitudinal and temperature trends in bay anchovy 412 consumption between striped bass and the other predators were likely related to spatiotemporal 413 differences in predator-prey overlap. Bay anchovy tend to be more abundant in the mid-bay in 414 the summer months, prior to moving to the lower bay and inner continental shelf to overwinter 415 (Wang and Houde 1995; Jung and Houde 2004). Summer flounder and weakfish, exhibit life 416 history strategies that favor use of the lower bay during warmer months (Latour et al. 2008; Able 417 and Fahay 2010), opposing the distributional patterns of the anadromous striped bass that tends 418 to favors the upper bay with higher densities in cold months. Thus, use of diets to infer relative 419 prey availability is challenging when both the prey and its predators exhibit different migratory 420 life histories. Regarding depth, the observed dietary trends correspond with previous work 421 suggesting that, although bay anchovy occur at a variety of depths, they tend to be more rare in 422 deeper waters $>25 \mathrm{~m}$ (Houde and Zastrow 1991). 
The trends of bivalve and polychaete consumption revealed broad-scale patterns in the

424 availability of macrobenthic prey for demersal fishes in Chesapeake Bay. These patterns were

425 detected within each of the two general prey groups, despite the need to aggregate numerous taxa

426 for logistical reasons. The decline of bivalve consumption and increase of polychaete

427 consumption in mid-latitude, mesohaline waters could be influenced by two principal

428 mechanisms relating to prey availability. First, regional biogeography and physico-chemical

429 preferences (e.g., salinity, sediment type) largely dictate the bay regions in which individual

430 macrobenthic species reside (Holland et al. 1987; Diaz and Schaffner 1990). For example,

431 Macoma and Gemma clams favor the more moderate salinities of the mid- to upper-bay, while

432 Ensis and Tagelus reside in more polyhaline, low-latitude waters (Diaz and Schaffner 1990).

433 Thus, latitudinal trends of bivalve and polychaete prey are an amalgamation of effects generated

434 from individual species that comprise each of the macrobenthic prey groups. A second potential

435 mechanism relates to chronic and acute habitat degradation. Extensive seasonal hypoxia caused

436 by eutrophication, physical stratification, and bacterial remineralization of organic matter is a

437 dominant environmental feature in the bay from June to August, persisting up to 3 months in

438 some areas (Murphy et al. 2011). Hypoxia diminishes macrobenthic productivity and biomass

439 more strongly in deeper mid-bay waters relative to upper and lower bay regions during the

440 summer months (Holland et al. 1987; Kemp et al. 2005). This decreased production may have

441 contributed to the declines in mid-bay bivalve consumption, whereas the increased dietary

442 occurrence of polychaetes in the mid-bay could be attributed to their greater tolerance of low

443 oxygen conditions relative to bivalves (Vaquer-Sunyer and Duarte 2008; Sturdivant et al. 2013)

444 or their tendency to more quickly recolonize benthic habitats once waters become re-oxygenated

445 (Rosenberg et al. 2002). Effects of hypoxia on mid-bay macrobenthic prey availability are not 
446 isolated to summer, as habitat degradation and seasonal hypoxia-induced mortality have shifted

447 the annual benthic community to smaller, shorter-lived species with lower standing stock

448 biomass (Holland et al. 1987; Kemp et al. 2005). Indeed, the latitudinal trend in bivalve

449 consumption was detected in all sampled months (A. Buchheister, unpublished data), suggesting 450 that species biogeographical distributions and long-term degradation of mid-bay habitats may be

451 more influential on macrobenthic consumption than direct seasonal hypoxic effects, particularly

452 considering that fishes avoid the low oxygen waters (Buchheister et al. 2013).

\section{Annual patterns in prey consumption}

455 Despite the lack of concordance between indices of prey abundance and consumption

456 overall, there was strong evidence of prey availability regulating annual consumption indices of

457 individual Chesapeake Bay predators, as supported in many other systems (Fahrig et al. 1993;

458 Mills et al. 2007; Dwyer et al. 2010; Pálsson and Björnsson 2011). The strongest empirical

459 indication that prey availability was involved in the annual trends was the coherence in peak

460 consumption of mysids, bivalves, and bay anchovy by predators with varied feeding preferences,

461 foraging modes, and distributional patterns. For example, two benthivorous species (Atlantic

462 croaker and scup) exhibited the same 2003 peak in mysid consumption as other zooplanktivorous

463 and piscivorous species (Northern searobin, summer flounder, weakfish), despite having diets

464 that do not typically target mysids (Buchheister and Latour 2015). Also, an upper bay species

465 (white perch) demonstrated a similar bivalve consumption peak as other lower bay predators,

466 even though the bivalve genera that predominate in these regions differ with Macoma clams in

467 the mid and upper bay and Ensis and Tagelus clams in the lower bay. These synchronous dietary

468 patterns likely relate to 1) the density-dependent feeding behavior of animals (Holling 1959), and 
2) the opportunistic feeding strategies that evolved to allow fishes to exploit spatiotemporallypatchy prey resources in dynamic, heterogeneous environments (Gerking 1994).

472 prey production during certain years (mysids - 2003; bivalves - 2008; bay anchovy - 2010) that

473 were utilized by a variety of predators that adapted to the greater prey availability. For example,

474 mysid consumption was correlated with mean annual spring temperature, spring salinity, and 475 surface chlorophyll-a (A. Buchheister, unpublished data), with 2003 being a distinct year in the 476 environmental time series as with the annual consumption indices. Those conditions could have 477 contributed to greater mysid production through bottom-up processes including improved local 478 reproduction during the spring spawning event, greater overall phytoplankton food availability 479 that improved juvenile or adult survival, or greater immigration of mysids from coastal waters 480 (Hopkins 1965, Ezzack and Corey 1979). Indeed, bottom-up mechanisms have been implicated 481 as drivers of ecosystem structure, fish recruitment, and fisheries landings in the Chesapeake Bay 482 and Mid-Atlantic Bight (Frank et al. 2007; Hare and Able 2007), and the dietary trends 483 documented are consistent with such donor control in food webs. However, any speculations on 484 specific mechanisms driving pulses in production of mysids, bay anchovy, or bivalves require 485 more directed and targeted research.

486 The general lack of concordance between prey abundance indices and the consumption 487 indices can be partially explained by 1) biases in prey sampling (whether by survey gear or by 488 predators) and 2) the different spatiotemporal scales represented by each index. First, possible 489 survey biases include: the long-term benthic monitoring program excluding Maryland waters $490>12 \mathrm{~m}$; that survey only sampling from July to September (after the macrobenthic biomass is 491 affected by summertime hypoxia); and the bay anchovy index being derived from a bottom trawl 
492 survey that is not optimal for sampling pelagic species. Predator consumption biases largely take 493 the form of prey selectivity (Eggers 1977; Juanes 1994), but annual consumption trends were 494 mirrored by the annual effects from the binomial models, whose presence/absence data tend to 495 be less biased by prey selectivity than gravimetric diet estimates (Link 2004; Baker et al. 2014). 496 Second, inference at the broad, annual scale can be obfuscated by variation in distributional 497 changes and spatiotemporal overlap of predators and prey. For example, the absence of peaks in 498 mysid consumption by striped bass and spotted hake in 2003 is likely due to the absence of these 499 predators in lower latitudes from July to September, where mysids appear more concentrated and 500 when mysid biomass peaks (Hulburt 1957; Hopkins 1965). Use of multiple predators with 501 contrasting life histories helped identify incongruous overlap situations such as this, but 502 interpretation of patterns is more challenging when both predator and prey are highly mobile (as 503 was the case for bay anchovy and their predators). Inadequate contrast in annual prey densities 504 has been identified as another complicating factor in detecting density-dependent diet signals 505 (Pinnegar et al. 2003). Also, indices of prey standing stocks may not be fully representative of 506 prey production rates, particularly for shorter lived prey groups with multiple or continuous 507 recruitment events throughout the year.

509 Methodological considerations

510 When modeling the consumption of an individual prey group, there is a potential for 511 interactions among prey caused largely by prey selectivity and prey switching (Eggers 1977;

512 Juanes 1994; Stefánsson and Pálsson 1997), such that the consumption of one prey influences the 513 consumption of another. There is some evidence of prey interaction between mysids and bay 514 anchovy (Buchheister 2013), but the interaction is confounded by the strong opposing 
515 ontogenetic trends in consumption for these two prey. The decreased likelihood of mysid

516 consumption when bay anchovy are present in a stomach (Buchheister 2013) could be driven

517 more by the size-based shifts in feeding as opposed to active prey selection (Juanes 1994), or by

518 patchiness of prey that can reduce the likelihood of joint occurrence of prey. Undoubtedly, prey

519 selectivity and the choices predators make at small scales can influence broader consumptive

520 trends of multiple prey, but disentangling these effects from other system interactions, indirect

521 food web effects, and spatiotemporal changes in predator-prey overlap require continued

522 research.

523 Generalized additive mixed effects models provided a powerful and flexible approach for 524 drawing more robust statistical inferences from stomach content data. The biggest advantages of 525 these models included the ability to 1) appropriately handle the excessive number of zeros in an 526 approach that is ecologically meaningful, 2) account for the correlation structure of the

527 hierarchical sampling design that is common in fisheries surveys, 3) incorporate a variety of 528 categorical and continuous explanatory variables, 4) account for nonlinear effects of covariates

529 on the response, and 5) maintain diet information at the individual fish level, to avoid pooling 530 data as is needed for average-based analytical methods (e.g., pooling predators into size classes

531 was not required). However, as with other statistical modeling, GAMM convergence was largely

532 predicated on having sufficient sample sizes for models of greater complexity. Proxies for 533 goodness of fit and precision of covariate effects were poor in some cases, but this is largely

534 attributable to the large variability in ecological datasets that are typically noisy. The major

535 dietary patterns and general conclusions of the study where not altered by the exclusion of the

536 random station effect (nor replacing it with a random stratum effect), but accounting for the non-

537 independence of fish is more statistically valid and helps avoid erroneous conclusions (Hurlbert 
538 1984, Millar and Anderson 2004). Although GAMMs have been described as being on "the

539 frontier of statistical research" (Zuur et al. 2009), these and related methods are being advanced

540 quickly and are becoming more accessible to researchers (Wood 2006; Zuur et al. 2009); thus,

541 they are rapidly being integrated into the statistical toolboxes of many ecologists and fisheries

542 scientists (e.g., Venables and Dichmont 2004; Ciannelli et al. 2008).

\section{Implications}

545 Comprehensive, spatiotemporally-extensive trophic studies such as this work help

546 elucidate the trophic relationships and drivers that structure ecosystems, and can contribute to

547 implementation of EBFM. The coherence in annual prey consumption indices of multiple

548 predators supports their utility as indicators of relative prey abundance that could augment

549 current prey sampling surveys (e.g., Mills et al. 2007), and such diet metrics may be particularly

550 useful for monitoring or hindcasting key prey groups, such as mysids, for which systematic

551 sampling does not exist. EBFM applications of this type of research include parameterization of

552 multispecies and ecosystem models (Pauly et al. 2000), use of dietary indices as ecosystem

553 indicators (Dwyer et al. 2010), empirical information for helping parameterize prey

554 vulnerabilities within foraging sub-models (Garrison et al. 2010), fitting of functional response

555 curves if consumptions are expressed as rates (Moustahfid et al. 2010), and potentially the use of

556 diet time-series as additional tuning indices for ecosystem models. Continued research on trophic

557 dynamics, particularly focused on long time periods and broader spatial extents, will provide

558 valuable information on fish and food web ecology to support EBFM at the scales most pertinent

559 to resource management. 


\section{Acknowledgements}

562 The authors recognize the outstanding work of the ChesMMAP staff for collecting and

563 maintaining survey and diet data, especially C. F. Bonzek and J. Gartland. The authors also thank

564 P. D. Lynch, K. L. Sobocinski, and M. A. Stratton for thoughtful discussions and support.

565 ChesMMAP was funded by the NOAA Chesapeake Bay Office, the Virginia Environmental

566 Endowment, the U.S. Fish and Wildlife Service, and the Virginia Marine Resources

567 Commission. Research support was provided by a Virginia Sea Grant graduate fellowship, the

568 National Science Foundation (Award Number OCE-1041713), a VIMS Council fellowship, and

569 an International Women's Fishing Association scholarship. J. E. Duffy, J. S. Link, T. J. Miller,

570 T. T. Sutton, and three anonymous reviewers provided constructive comments on earlier drafts of

571 this manuscript. This paper is Contribution No. XXXX of the Virginia Institute of Marine

572 Science, College of William \& Mary and publication number XXX of the University of

573 Maryland Center for Environmental Science, Chesapeake Biological Laboratory. 


\section{$574 \quad$ References}

575 Able, K.W., and Fahay, M.P. 2010. Ecology of estuarine fishes - Temperate waters of the western North Atlantic. The Johns Hopkins University Press, Baltimore, MD.

Baird, D., and Ulanowicz, R.E. 1989. The seasonal dynamics of the Chesapeake Bay ecosystem. Ecol. Modell. 59: 329-364.

Baker, R., Buckland, A., and Sheaves, M. 2013. Fish gut content analysis: robust measures of diet composition. Fish Fish. 15:170-177. doi: 10.1111/faf.12026.

Bogstad, B., Penningtonb, M., and Varlstad, J.H. 1995. Cost-efficient survey designs for estimating food consumption by fish. Fish. Res. 23: 37-46.

Buchheister, A. 2013. Structure, drivers, and trophic interactions of the demersal fish community in Chesapeake Bay. PhD Thesis. College of William and Mary. Williamsburg, VA, USA.

Buchheister, A., Bonzek, C.F., Gartland, J., and Latour, R.J. 2013. Patterns and drivers of the demersal fish community of Chesapeake Bay. Mar. Ecol. Prog. Ser. 481: 161-180. doi: $10.3354 /$ meps 10253 .

Buchheister A., Latour, R.J. 2015. Diets and trophic guild structure of a diverse fish assemblage in Chesapeake Bay, USA. J. Fish. Biol. 86:967-992. doi: 10.1111/jfb.12621.

Buchheister A., Wilberg, M.J., Miller, T.J., and Latour, R.J. In review. Simulating bottom-up effects on predator productivity and consequences for the rebuilding timeline of a depleted population. Ecol. Modell.

593 Burnham, K.P., and Anderson, D.R. 2002. Model Selection and Multimodel Inference: A Practical Information-Theoretic Approach. In 2nd edition. Springer, New York, New York. 
596 Carpenter, S.R., Kitchell, J.F., and Hodgson, J.R. 1985. Cascading trophic interactions and lake 597 productivity. Bioscience 35: 634-639.

598 Christensen, V., Beattie, A., Buchanan, C., Ma, H., Martell, S.J.D., Latour, R.J., Preikshot, D., 599 Sigrist, M.B., Uphoff, J.H., Walters, C.J., Wood, R.J., and Townsend, H. 2009. Fisheries ecosystem model of the Chesapeake Bay: methodology, parameterization, and model exploration. U.S. Dep. Commer. NOAA Tech. Memo. NMFS-F/SPO: 1-146. U.S.

Ciannelli, L., Fauchald, P., Chan, K.S., Agostini, V.N., and Dingsør, G.E. 2008. Spatial fisheries ecology: Recent progress and future prospects. J. Mar. Syst. 71: 223-236. doi: 10.1016/j.jmarsys.2007.02.031.

Cronin, L.E., Daiber, J.C., and Hulbert, E.M. 1962. Quantitative seasonal aspects of zooplankton 607 in the Delaware River estuary. Chesap. Sci. 3: 63-93.

Diaz, R.J., and Schaffner, L.C. 1990. The Functional Role of Estuarine Benthos. In Perspectives on the Chesapeake Bay, 1990 - Advances in estuarine sciences. Edited by M. Haire and E.C. Krome. Chesapeake Research Consortium, Report No CBP/TRS41/90, Gloucester Point, VA. pp. 25-56.

Dwyer, K.S., Buren, a., and Koen-Alonso, M. 2010. Greenland halibut diet in the Northwest Atlantic from 1978 to 2003 as an indicator of ecosystem change. J. Sea Res. 64: 436-445. Elsevier B.V. doi: 10.1016/j.seares.2010.04.006.

616 Ezzack, D.S.F., and Corey, S. 1979. The life history and distribution of Neomysis americana (Smith) (Crustacea, Mysidacea) in Passamaquoddy Bay eastern coast of North America from southern. Can. J. Zool. 57: 785-793. 
619 Fahrig, L., Lilly, G.R., and Miller, D.S. 1993. Predator stomachs as sampling tools for prey 620 distribution, Atlantic cod (Gadus morhua) and capelin (Mallotus villosus). Can. J. Fish. $621 \quad$ Aquat. Sci. 50: 1541-1547.

622 Frank, K.T., Petrie, B., and Shackell, N.L. 2007. The ups and downs of trophic control in 623 continental shelf ecosystems. Trends Ecol. Evol. 22: 236-242.

624 Gaichas, S., Bundy, A., Miller, T., Moksness, E., and Stergiou, K. 2012. What drives marine fisheries production? Mar. Ecol. Prog. Ser. 459: 159-163. doi: 10.3354/meps09841.

Garrison, L.P., Link, J.S., Kilduff, D.P., Cieri, M.D., Muffley, B., Vaughan, D.S., Sharov, A., Mahmoudi, B., and Latour, R.J. 2010. An expansion of the MSVPA approach for

Gerking, S.D. 1994. Feeding ecology of fish. Academic Press, San Diego.

631 Hare, J.A., and Able, K.W. 2007. Mechanistic links between climate and fisheries along the east coast of the United States: explaining population outbursts of Atlantic croaker (Micropogonias undulatus). Fish. Oceanogr. 16: 31-45.

636 Holland, A.F., Shaughnessy, A.T., and Hiegel, M.H. 1987. Long-term variation in mesohaline Chesapeake Bay macrobenthos: spatial and temporal patterns. Estuaries 10: 227-245.

Holling, C.S. 1959. The components of predation as revealed by a study of small-mammal predation of the European pine sawfly. Can. Entomol. 91: 293-320. Chesap. Sci. 6: 86-91. 
642 Hostens, K., and Mees, J. 1999. The mysid-feeding guild of demersal fishes in the brackish zone of the Westerschelde estuary. J. Fish Biol. 55: 704-719.

644 Houde, E.D. 2006. A fisheries ecosystem plan for the Chesapeake Bay. In Fisheries ecosystem planning for Chesapeake Bay. Edited by Chesapeake Bay Fisheries Ecosystem Advisory Panel. American Fisheries Society, Bethesda, MD. p. 450.

647 Houde, E.D., and Zastrow, C.E. 1991. Bay anchovy. In Habitat requirements for Chesapeake Bay living resources, 2nd edition. Edited by S.L. Funderburk, J.A. Mihursky, and D. Riley. Chesapeake Bay Program, Annapolis, MD. pp. 1-12.

Hulburt, E. 1957. The distribution of Neomysis americana in the estuary of the Delaware River. Limnol. Oceanogr. 2: 1-11.

Hunsicker, M.E., Ciannelli, L., Bailey, K.M., Buckel, J.A., White, W.J., Link, J.S., Essington, T.E., Gaichas, S., Anderson, T.W., Brodeur, R.D., Chan, K.-S., Chen, K., Englund, G., Frank, K.T., Freitas, V., Hixon, M.A., Hurst, T., Johnson, D.W., Kitchell, J.F., Reese, D., Rose, G.A., Sjodin, H., Sydeman, W.J., van der Veer, H.W., Vollset, K., and Zador, S.

659 Hurlbert, S.H. 1984. Pseudoreplication and the design of ecological field experiments. Ecol. Monogr. 54: 187-211.

661 Juanes, F. 1994. What determines prey size selectivity in piscivorous fishes? In Theory and 662 application in fish feeding ecology. Edited by D.J. Stouder and K.L. Fresh. Carolina University Press, Columbia. pp. 79-100. 
664 Jumars, P.A. 2007. Habitat coupling by mid-latitude, subtidal, marine mysids: Import-subsidized 665 omnivores. Oceanogr. Mar. Biol. An Annu. Rev. 45: 89-138.

666 Jung, S., and Houde, E.D. 2004. Recruitment and spawning-stock biomass distribution of bay 667 anchovy (Anchoa mitchilli) in Chesapeake Bay. Fish. Bull. 102: 63-77.

668 Kemp, W., Boynton, W., Adolf, J., Boesch, D., Boicourt, W., Brush, G., Cornwell, J., Fisher, T., 669 Glibert, P., Hagy, J., Harding, L., Houde, E., Kimmel, D., Miller, W., Newell, R., Roman, M., Smith, E., and Stevenson, J. 2005. Eutrophication of Chesapeake Bay: historical trends and ecological interactions. Mar. Ecol. Prog. Ser. 303: 1-29. doi: $10.3354 / \operatorname{meps} 303001$.

Kerr, S.R., and Dickie, L.M. 2001. The biomass spectrum: a predator-prey theory of aquatic production. In Complexity in Ecological Systems. Edited by T.F.H. Allen and D.W. Roberts. Columbia University Press, New York.

Kimura, D.K., and Somerton, D.A. 2006. Review of Statistical Aspects of Survey Sampling for Marine Fisheries. Rev. Fish. Sci. 14: 245-283. doi: 10.1080/10641260600621761.

Latour, R.J., Brush, M.J., and Bonzek, C.F. 2003. Toward ecosystem-based fisheries management: Strategies for multispecies modeling and associated data requirements. Fisheries 28: 10-22.

Latour, R.J., Gartland, J., Bonzek, C.F., and Johnson, R.A. 2008. The trophic dynamics of summer flounder (Paralichthys dentatus) in Chesapeake Bay. Fish. Bull. 106: 47-57.

Link, J.S. 2002. Ecological considerations in fisheries management: When does it matter? Fisheries 27: 10-17. scales. Mar. Ecol. Ser. 269: 265-275. 
Link, J.S. 2010. Ecosystem-based fisheries management: confronting tradeoffs. Cambridge

688

689

690

691

692

693

694

695

696

697

698

699

700

701

702

703

704

705

706

707

708 University Press, New York.

Link, J.S., Bundy, A., Overholtz, W.J., Shackell, N., Manderson, J., Duplisea, D., Hare, J., KoenAlonso, M., and Friedland, K.D. 2011. Ecosystem-based fisheries management in the Northwest Atlantic. Fish Fish. 12: 152-170. doi: 10.1111/j.1467-2979.2011.00411.x.

Mauchline, J. 1980. The biology of mysids and euphausiids. Adv. Mar. Biol. 18: 1-682.

Maunder, M.N., and Punt, A.E. 2004. Standardizing catch and effort data: a review of recent approaches. Fish. Res. 70: 141-159. doi: 10.1016/j.fishres.2004.08.002.

Millar, R.B., and Anderson, M.J. 2004. Remedies for pseudoreplication. Fish. Res. 70: 397-407. doi: 10.1016/j.fishres.2004.08.016.

Mills, K.L., Laidig, T., Ralston, S., and Sydeman, W.J. 2007. Diets of top predators indicate pelagic juvenile rockfish (Sebastes spp.) abundance in the California Current System. Fish. Oceanogr. 16: 273-283. doi: 10.1111/j.1365-2419.2006.00429.x.

Moustahfid, H., Tyrrell, M.C., Link, J.S., Nye, J.A., Smith, B.E., and Gamble, R.J. 2010. Functional feeding responses of piscivorous fishes from the northeast US continental shelf. Oecologia 163: 1059-67. doi: 10.1007/s00442-010-1596-2.

Murphy, R.R., Kemp, W.M., and Ball, W.P. 2011. Long-term trends in Chesapeake Bay seasonal hypoxia, stratification, and nutrient loading. Estuaries and Coasts 34: 1293-1309. doi: 10.1007/s12237-011-9413-7.

Nakagawa, S., and Schielzeth, H. 2013. A general and simple method for obtaining $\mathrm{R}^{2}$ from generalized linear mixed-effects models. Methods Ecol. Evol. 4: 133-142. doi: 10.1111/j.2041-210x.2012.00261.x. 
709 Pálsson, Ó.K., and Björnsson, H. 2011. Long-term changes in trophic patterns of Iceland cod and 710 linkages to main prey stock sizes. ICES J. Mar. Sci. 68: 1488-1499. doi: 10.1093/icesjms/fsr057.

712 Pauly, D., Christensen, V., and Walters, C. 2000. Ecopath, Ecosim, and Ecospace as tools for evaluating ecosystem impact of fisheries. ICES J. Mar. Sci. 57: 697-706.

714 Pinnegar, J.K., Trenkel, V.M., Tidd, A.N., Dawson, W.A., and Du Buit, M.H. 2003. Does diet in 715 Celtic Sea fishes reflect prey availability? J. Fish Biol. 63: 197-212. doi: 10.1046/j.10958649.2003.00204.x.

R Core Team. 2013. R: A language and environment for statistical computing. R Foundation for Statistical Computing, Vienna, Austria.

Rosenberg, R., Agrenius, S., Hellman, B., Nilsson, H., and Norling, K. 2002. Recovery of marine benthic habitats and fauna in a Swedish fjord following improved oxygen

Santos, M., German, I., Correia, D., Read, F., Martinez Cedeira, J., Caldas, M., López, A., Velasco, F., and Pierce, G. 2013. Long-term variation in common dolphin diet in relation to prey abundance. Mar. Ecol. Prog. Ser. 481: 249-268. doi: 10.3354/meps 10233.

Scharf, F.S., Buckel, J.A., and Juanes, F. 2002. Size-dependent vulnerability of juvenile bay anchovy Anchoa mitchilli to bluefish predation: Does large body size always provide a refuge? Mar. Ecol. Prog. Ser. 233: 241-252.

729

Scharf, F.S., Juanes, F., and Rountree, R.A. 2000. Predator size - prey size relationships of marine fish predators: interspecific variation and effects of ontogeny and body size on trophic-niche breadth. Mar. Ecol. Ser. 208: 229-248. 
731 Sprugel, D.G. 1983. Correcting for bias in log-transformed allometric equations. Ecology 64:

$732 \quad 209-210$.

733 Stefánsson, G., and Pálsson, Ó.K. 1997. Statistical evaluation and modelling of the stomach 734 contents of Icelandic cod (Gadus morhua). Can. J. Fish. Aquat. Sci. 54: 169-181.

735 Sturdivant, S., Seitz, R., and Diaz, R. 2013. Effects of seasonal hypoxia on macrobenthic 736 production and function in the Rappahannock River, Virginia, USA. Mar. Ecol. Prog. 737 Ser. 490: 53-68. doi: 10.3354/meps10470.

738 Tuckey, T.D., and Fabrizio, M.C. 2012. Estimating Relative Juvenile Abundance of Ecologically 739 Important Finfish in the Virginia Portion of Chesapeake Bay. Gloucester Point, VA.

$740 \quad$ Available from http://www.vims.edu/research/departments/fisheries/programs/juvenile surveys/data pro

743 Vaquer-Sunyer, R., and Duarte, C.M. 2008. Thresholds of hypoxia for marine biodiversity. Proc. Natl. Acad. Sci. 105: 15452-7. doi: 10.1073/pnas.0803833105.

745 Venables, W.N., and Dichmont, C.M. 2004. GLMs, GAMs and GLMMs: an overview of theory 746 for applications in fisheries research. Fish. Res. 70: 319-337. doi:

$747 \quad$ 10.1016/j.fishres.2004.08.011.

748 Wang, S., and Houde, E.D. 1995. Distribution, relative abundance, biomass and production of 749 bay anchovy Anchoa mitchilli in the Chesapeake Bay. Mar. Ecol. Prog. Ser. 121: 27-38.

750 Whipple, S.J., Link, J.S., Garrison, L.P., and Fogarty, M.J. 2000. Models of predation and

751 fishing mortality in aquatic ecosystems. Fish Fish. 1: 22-40.

752 Whitely, G.C. 1948. The distribution of the larger planktonic Crustacea on Georges Bank. Ecol. 753 Monogr. 18: 233-264. 
754 Wood, S. 2012. gamm4: Generalized additive mixed models using mgcv and lme4. R package 755 version 0.1-6. Available from http://cran.r-project.org/package=gamm4

756 Wood, S.N. 2006. Generalized additive models: an introduction with R. In Texts in statistical 757 science. Chapman \& Hall/CRC, Boca Raton, FL.

758 Wootton, R.J. 1998. Ecology of Teleost Fishes. In Fish and Fisheries, 2nd edition. Kluwer 759 Academic Publishers, Boston.

760 Zuur, A.F., Ieno, E.N., and Elphick, C.S. 2010. A protocol for data exploration to avoid common $761 \quad$ statistical problems. Methods Ecol. Evol. 1: 3-14. doi: 10.1111/j.2041210X.2009.00001.x.

763 Zuur, A.F., Ieno, Elena, N., Walker, N.J., Saveliev, A.A., and Smith, G.M. 2009. Mixed effects 764 models and extensions in ecology with R. Springer, New York. 
765 Table 1. Sample summaries for Chesapeake Bay predators collected for dietary analysis. Length measurements were recorded as fork

766 length (teleosts) or disc width (batoids). $\mathrm{N}_{\mathrm{s}}=$ Number of stations with predator captured, $\mathrm{N}_{\mathrm{f}}=$ Number of individual fish sampled for

767 stomachs, $\mathrm{P}_{\mathrm{e}}=$ percentage of fish stomachs that were empty. Numbers of fish containing key prey groups are indicated.

\begin{tabular}{|c|c|c|c|c|c|c|c|c|c|c|}
\hline \multirow[b]{2}{*}{ Predator } & \multicolumn{2}{|c|}{ Length $(\mathrm{mm})$} & \multirow[b]{2}{*}{$\mathrm{N}_{\mathrm{s}}$} & \multirow[b]{2}{*}{$N_{f}$} & \multirow[b]{2}{*}{$\mathrm{P}_{\mathrm{e}}$} & \multicolumn{5}{|c|}{ No. fish containing prey } \\
\hline & Range & Mean & & & & Any Prey & Mysid & Anchovy & Bivalve & Polychaete \\
\hline Atlantic croaker (Micropogonias undulatus) & $20-478$ & 242 & 977 & 3374 & 14 & 2914 & 458 & -- & 550 & 1753 \\
\hline clearnose skate (Raja eglanteria) & $84-519$ & 412 & 355 & 941 & 13 & 821 & -- & -- & 146 & -- \\
\hline kingfishes (Menticirrhus spp. )* & $45-383$ & 236 & 399 & 1077 & 18 & 882 & -- & -- & 179 & 178 \\
\hline northern puffer (Sphoeroides maculatus ) & $49-272$ & 156 & 407 & 1087 & 9 & 990 & -- & -- & 292 & 180 \\
\hline northern searobin (Prionotus carolinus ) & $40-223$ & 127 & 387 & 941 & 20 & 751 & 381 & -- & -- & -- \\
\hline scup (Stenotomus chrysops) & $69-223$ & 123 & 347 & 879 & 17 & 732 & 150 & -- & -- & 268 \\
\hline spot (Leiostomus xanthurus ) & $40-311$ & 156 & 616 & 2217 & 29 & 1581 & -- & -- & -- & 556 \\
\hline spotted hake (Urophycis regia) & $50-318$ & 147 & 244 & 609 & 19 & 491 & 323 & -- & -- & -- \\
\hline striped bass (Morone saxatilis ) & $92-1051$ & 372 & 1005 & 3868 & 33 & 2590 & 549 & 638 & -- & 707 \\
\hline summer flounder (Paralichthys dentatus ) & $129-750$ & 344 & 1501 & 4874 & 42 & 2828 & 1119 & 663 & -- & -- \\
\hline weakfish (Cynoscion regalis ) & $15-616$ & 211 & 1128 & 6699 & 25 & 4994 & 2301 & 1951 & -- & -- \\
\hline white perch (Morone americana) & $68-351$ & 202 & 524 & 2784 & 38 & 1739 & -- & -- & 278 & 510 \\
\hline
\end{tabular}

${ }^{*}$ Menticirrhus saxatilis and $M$. americanus combined. 
Table 2. Best binomial and positive generalized additive mixed models (GAMM) for each predator-prey combination. Inclusion $(+)$ and exclusion (blank) of covariates for the best fit models were determined through model selection using Akaike's Information Criterion $(Y R=$ Year; $L=$ Length; $L A=$ Latitude; $T=$ Temperature; $D=$ Depth $)$.

Inclusion of $Y R$ was forced in all models. A proxy for the deviance explained (\% Dev) by each model was determined by fitting a fixed-effects generalized additive model with the specified covariates.

\begin{tabular}{|c|c|c|c|c|c|c|c|c|c|c|c|c|c|}
\hline \multirow[b]{2}{*}{ Prey } & \multirow[b]{2}{*}{ Predator } & \multicolumn{6}{|c|}{ Binomial GAMM } & \multicolumn{6}{|c|}{ Positive GAMM } \\
\hline & & $Y R$ & $L$ & $L A$ & $T$ & $D$ & $\% \mathrm{Dev}$ & YR & $L$ & $L A$ & $T$ & $D$ & $\%$ Dev \\
\hline \multirow[t]{3}{*}{ Bay anchovy } & Summer flounder & + & + & + & + & + & 13.5 & + & + & & & & 5.4 \\
\hline & Striped bass & + & + & + & + & + & 17.0 & + & & + & & & 9.4 \\
\hline & Weakfish & + & + & + & + & & 8.7 & + & + & & & & 7.6 \\
\hline \multirow[t]{5}{*}{ Bivalve } & Atlantic croaker & + & + & + & & & 13.5 & + & + & + & & & 24.6 \\
\hline & Clearnose skate & + & & + & & & 16.9 & + & & & & & 22.3 \\
\hline & Kingfish & + & & + & + & & 22.6 & + & + & & & & 35.4 \\
\hline & Northern puffer & + & + & + & + & & 15.0 & + & + & & & & 20.0 \\
\hline & White perch & + & + & + & + & & 12.6 & + & + & & & & 15.0 \\
\hline \multirow[t]{7}{*}{ Mysid } & Atlantic croaker & + & + & & + & & 16.5 & + & & & & & 8.8 \\
\hline & Northern searobin & + & & + & & & 6.8 & + & + & & + & + & 15.7 \\
\hline & Scup & + & & & + & + & 13.5 & + & & & & & 6.0 \\
\hline & Spotted hake & + & + & & + & + & 19.3 & + & + & & + & + & 29.1 \\
\hline & Striped bass & + & + & + & + & & 19.0 & + & + & + & & & 24.3 \\
\hline & Summer flounder & + & + & + & + & + & 36.7 & + & + & + & & & 9.1 \\
\hline & Weakfish & + & + & + & + & + & 18.8 & + & + & & & & 12.8 \\
\hline \multirow[t]{7}{*}{ Polychaete } & Atlantic croaker & + & + & + & + & + & 8.9 & + & + & & & & 28.5 \\
\hline & Kingfish & + & + & & & & 6.9 & + & + & & & & 49.3 \\
\hline & Northern puffer & + & & + & & + & 9.5 & + & + & & & & 32.4 \\
\hline & Scup & + & + & + & & + & 8.0 & + & + & & & & 22.8 \\
\hline & Spot & + & + & + & & & 4.3 & + & + & & & & 16.7 \\
\hline & Striped bass & + & + & + & & + & 13.5 & + & + & & & & 10.6 \\
\hline & White perch & + & + & + & & + & 8.2 & + & + & + & & & 25.5 \\
\hline
\end{tabular}


Table 3. Pearson correlations among annual predator consumption indices and prey abundance indices (when available) for each of four prey groups ( $\mathrm{a}$ - bay anchovy; $\mathrm{b}$ mysids; c - bivalves; $\mathrm{d}$ - polychaetes). Correlations were calculated from logged values of annual consumption indices. Gray shading used to denote significance (alpha $=0.05$ ) without Bonferroni correction; bold used to denote significance with Bonferroni correction. Spot were omitted from polychaete correlations due to lack of sampling over the whole time series.

\begin{tabular}{|c|c|c|c|c|c|c|}
\hline a. Mysids & $\begin{array}{l}\text { 今 } \\
\text { ఝ }\end{array}$ & $\begin{array}{l}\frac{\bar{d}}{\overline{0}} \\
\text { 흔 } \\
\text { 흔 }\end{array}$ & $\begin{array}{l}\bar{\Phi} \\
\bar{\varpi} \\
\stackrel{0}{0} \\
\end{array}$ & 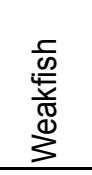 & 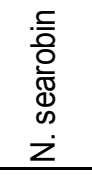 & 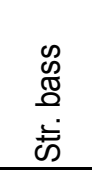 \\
\hline Flounder & 0.79 & & & & & \\
\hline Croaker & 0.88 & 0.69 & & & & \\
\hline Weakfish & 0.83 & 0.58 & 0.90 & & & \\
\hline N. searobin & 0.88 & 0.56 & 0.75 & 0.78 & & \\
\hline Str. bass & 0.05 & -0.15 & 0.11 & -0.07 & 0.33 & \\
\hline Sp. Hake & -0.14 & -0.45 & -0.09 & 0.03 & 0.03 & 0.33 \\
\hline b. Bay anchovy & 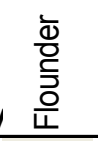 & 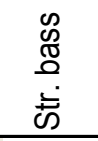 & 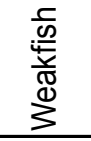 & & & \\
\hline Str. bass & 0.71 & & & & & \\
\hline Weakfish & -0.01 & 0.03 & & & & \\
\hline Index & 0.41 & 0.34 & 0.42 & & & \\
\hline c. Bivalves & 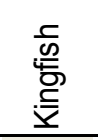 & $\begin{array}{l}\frac{\Phi}{\pi} \\
\frac{\pi}{\omega} \\
\dot{0} \\
\dot{0}\end{array}$ & $\begin{array}{l}\frac{5}{0} \\
\frac{0}{0} \\
\frac{0}{3}\end{array}$ & 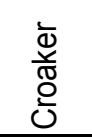 & $\begin{array}{l}\frac{\bar{\Phi}}{4} \\
\underline{\underline{z}} \\
\dot{z} \\
\end{array}$ & \\
\hline Cl. skate & 0.69 & & & & & \\
\hline W. perch & 0.41 & 0.72 & & & & \\
\hline Croaker & 0.20 & 0.49 & 0.31 & & & \\
\hline N. puffer & 0.23 & 0.30 & 0.40 & 0.35 & & \\
\hline Index & -0.12 & -0.13 & -0.10 & 0.18 & 0.74 & \\
\hline d. Polychaetes & $\begin{array}{l}\text { 을 } \\
\text { 心 }\end{array}$ & 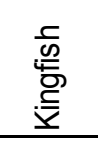 & $\begin{array}{l}\frac{1}{0} \\
\frac{0}{0} \\
\frac{0}{3} \\
\end{array}$ & 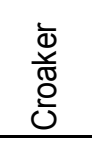 & $\begin{array}{l}\frac{\bar{\Phi}}{4} \\
\overline{\mathbf{z}} \\
\dot{z} \\
\end{array}$ & 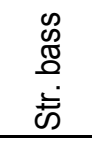 \\
\hline Kingfish & 0.05 & & & & & \\
\hline W. perch & 0.66 & 0.14 & & & & \\
\hline Croaker & 0.50 & 0.67 & 0.58 & & & \\
\hline N. puffer & 0.23 & -0.40 & 0.23 & 0.10 & & \\
\hline Str. bass & -0.67 & 0.33 & -0.34 & 0.04 & -0.36 & \\
\hline Index & 0.49 & 0.33 & 0.37 & 0.22 & 0.14 & -0.69 \\
\hline
\end{tabular}




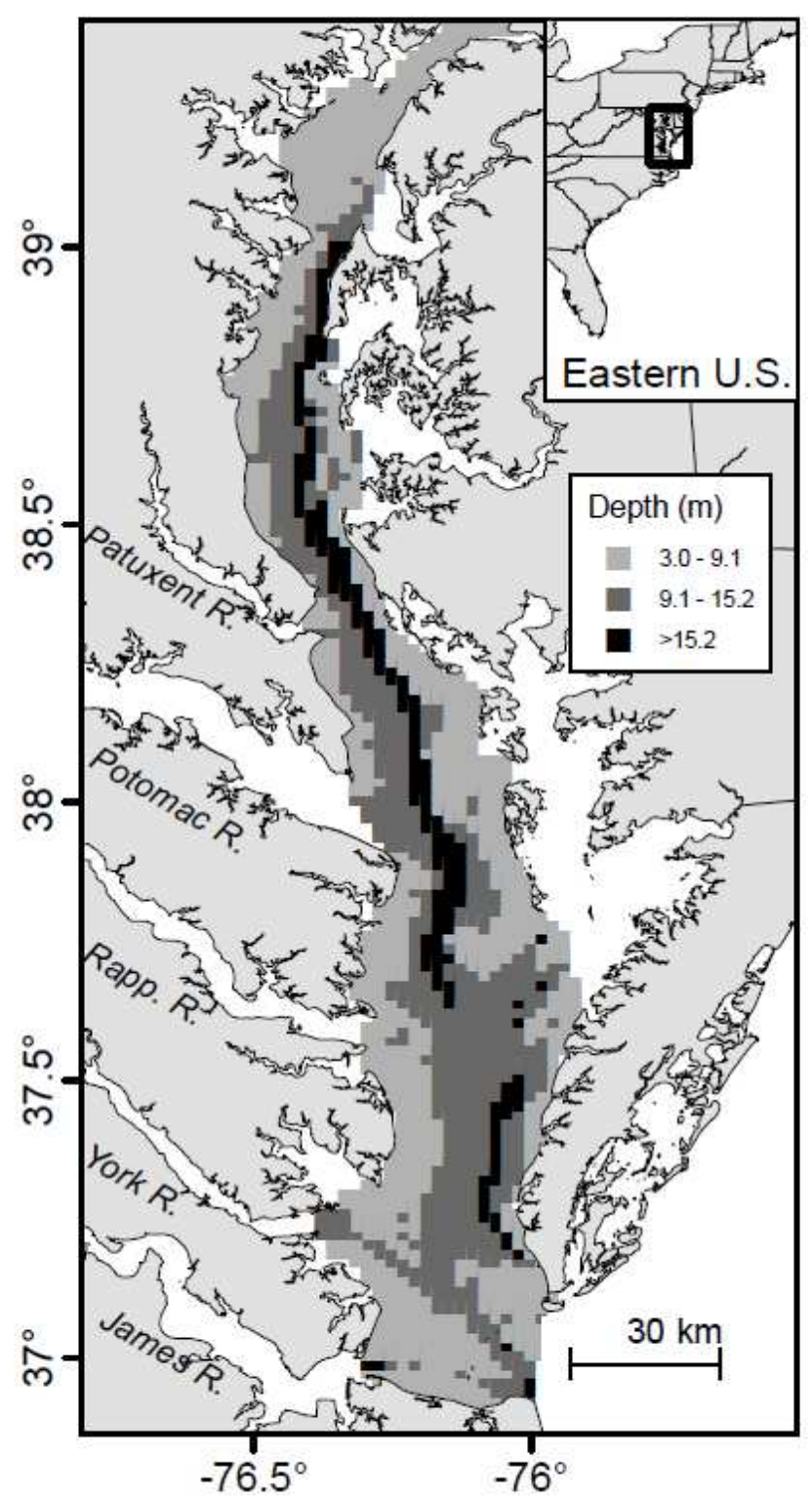

Fig. 1. Map of Chesapeake Bay mainstem areas sampled by the Chesapeake Bay Multispecies Monitoring and Assessment Program. Survey area is divided into $1 \mathrm{~km}^{2}$ grid cells and classified into three depth strata. Areas in white are not sampled by the survey. 


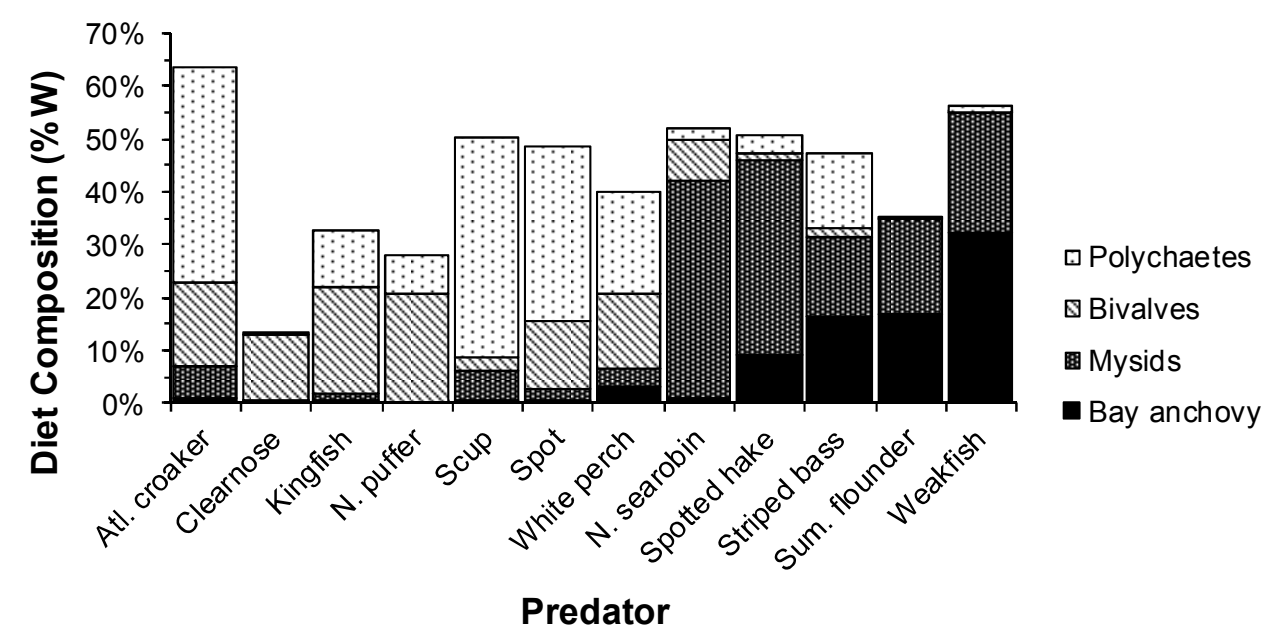

Fig. 2. Composition of predator diets (as $\%$ of stomach content weight) for twelve Chesapeake Bay fishes consuming four key prey groups (bay anchovy, mysids, bivalves, and polychaetes). The remainder of stomach contents were comprised of other prey. 

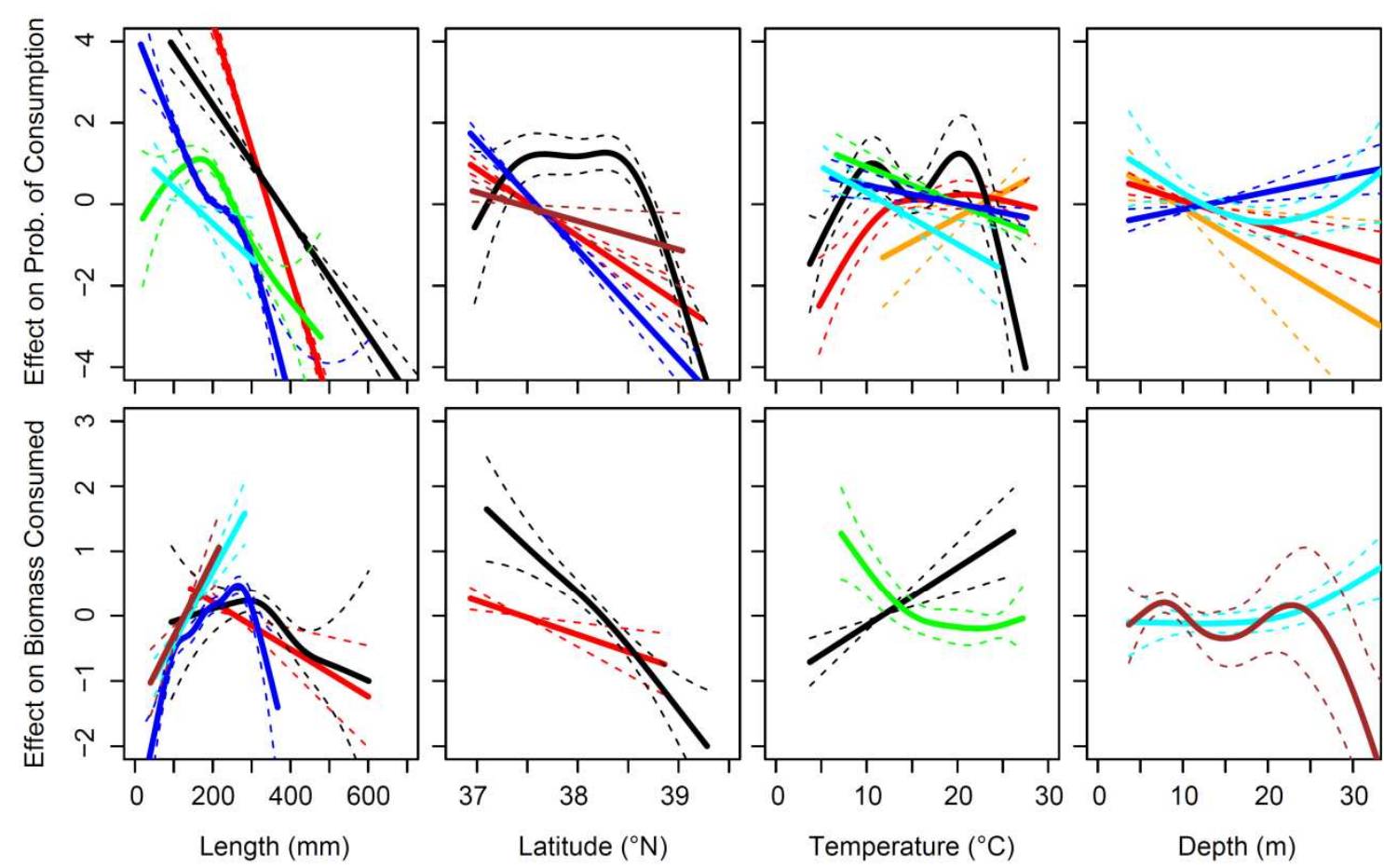

Predator

Atl. croaker

- N. searobin Scup Spotted hake

Striped bass

- Sum. flounder

— Weakfish

Fig. 3. Modeled effects of continuous covariates on consumption of mysids based on delta generalized additive mixed-effects models (GAMMs) for multiple Chesapeake Bay predators. Upper panels depict covariate effects on the relative probability (on the logit scale) of a predator stomach containing a mysid, based on a binomial GAMM. Lower panels depict covariate effects on the relative amount of mysids consumed (log of biomass) based on a positive GAMM. Dashed lines represent 95\% confidence limits for the estimated effects. Predator curves are not plotted if a covariate was not included in the best model. 

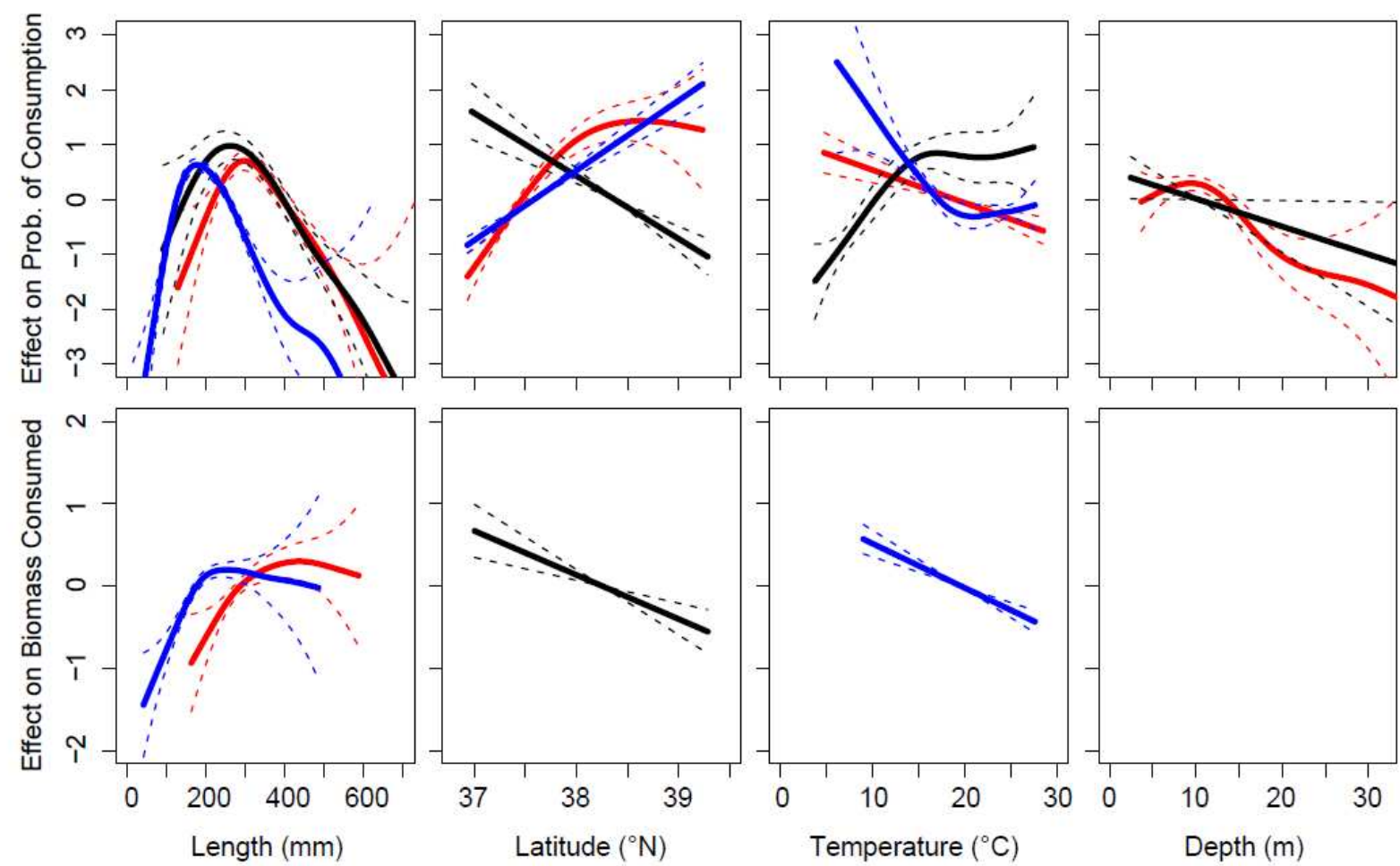

Predator

Striped bass

Sum. flounder

Weakfish

Fig. 4. Modeled effects of continuous covariates on consumption of bay anchovy based on delta generalized additive mixed-effects models (GAMMs) for multiple Chesapeake Bay predators. See Figure 3 for full description of plot. 

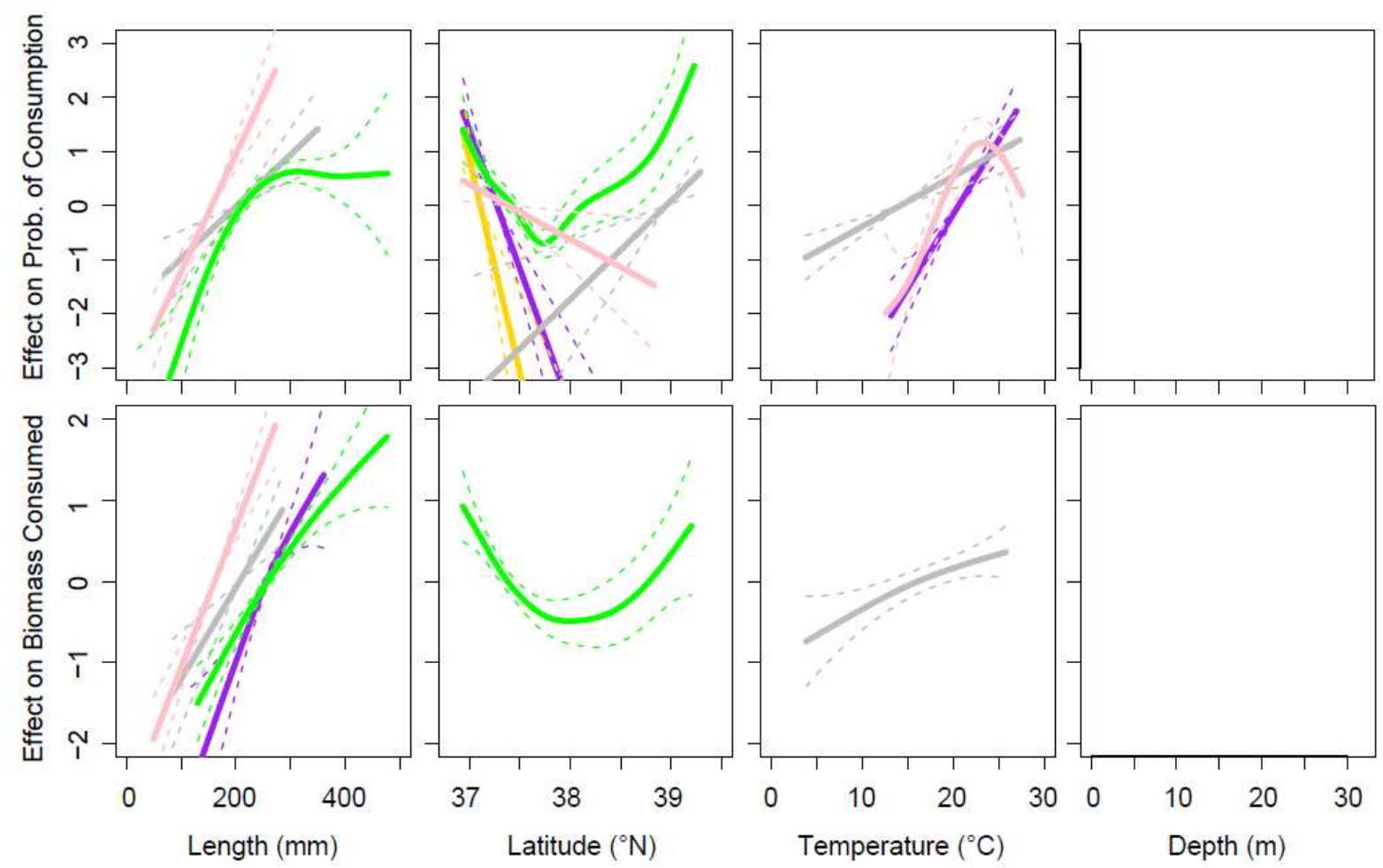

Fig. 5. Modeled effects of continuous covariates on consumption of bivalves based on delta generalized additive mixed-effects models (GAMMs) for multiple Chesapeake Bay predators. See Figure 3 for full description of plot. 

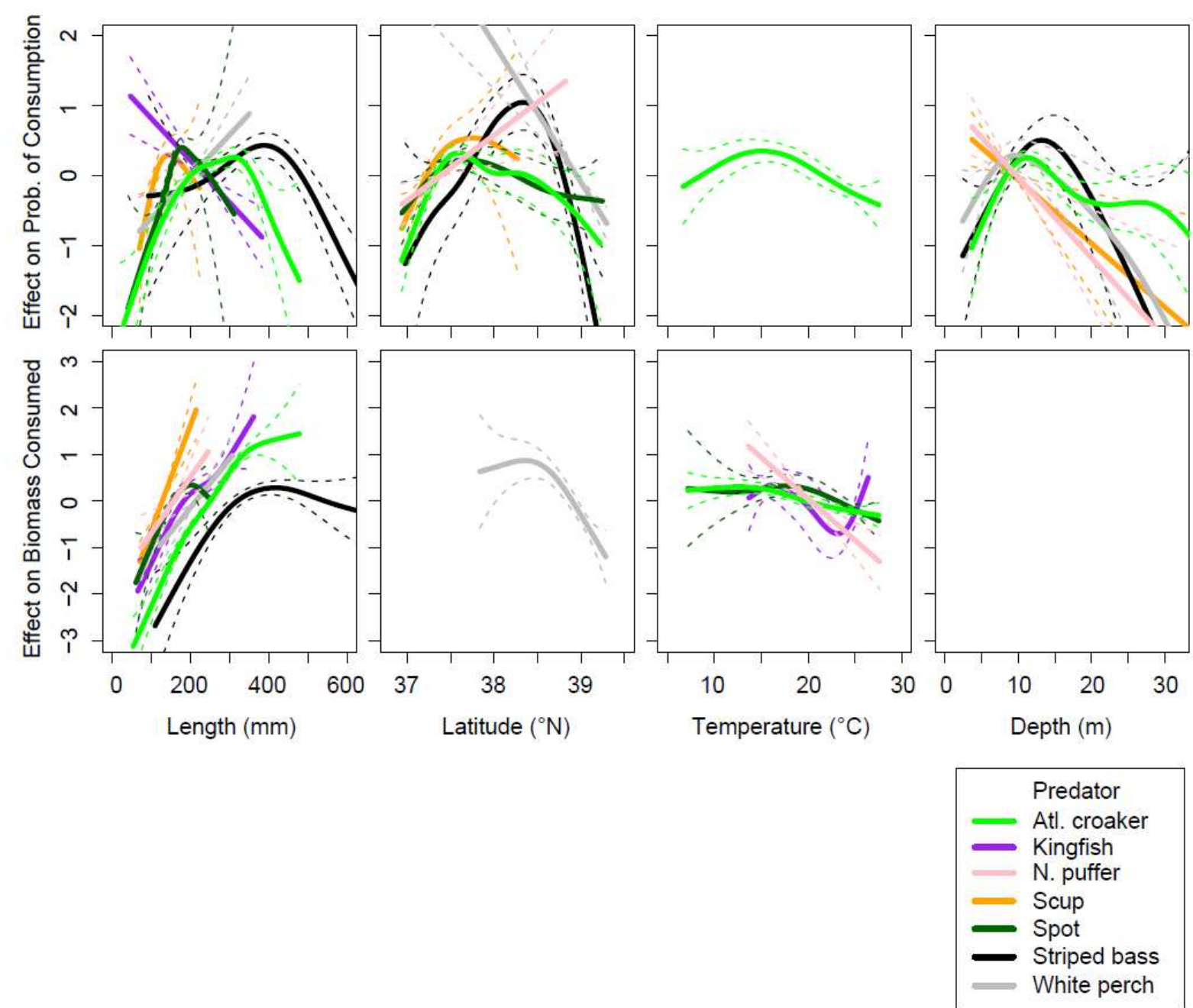

Fig. 6. Modeled effects of continuous covariates on consumption of polychaetes based on delta generalized additive mixed-effects models (GAMMs) for multiple Chesapeake Bay predators. See Figure 3 for full description of plot. 

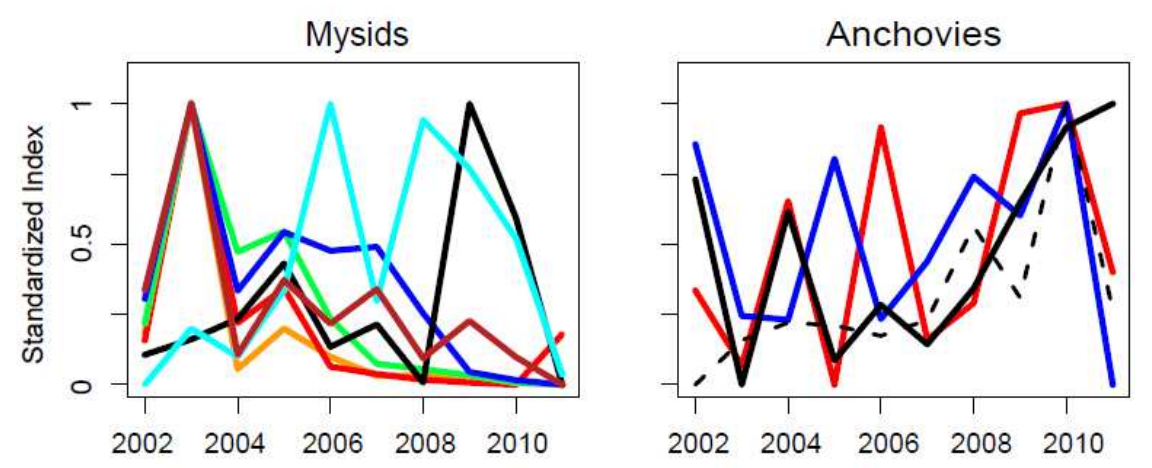

Consumption Index

Atl. croaker

Clearnose

- Kingfish

N. puffer

N. searobin 20022004200620082010

Scup

Bivalves
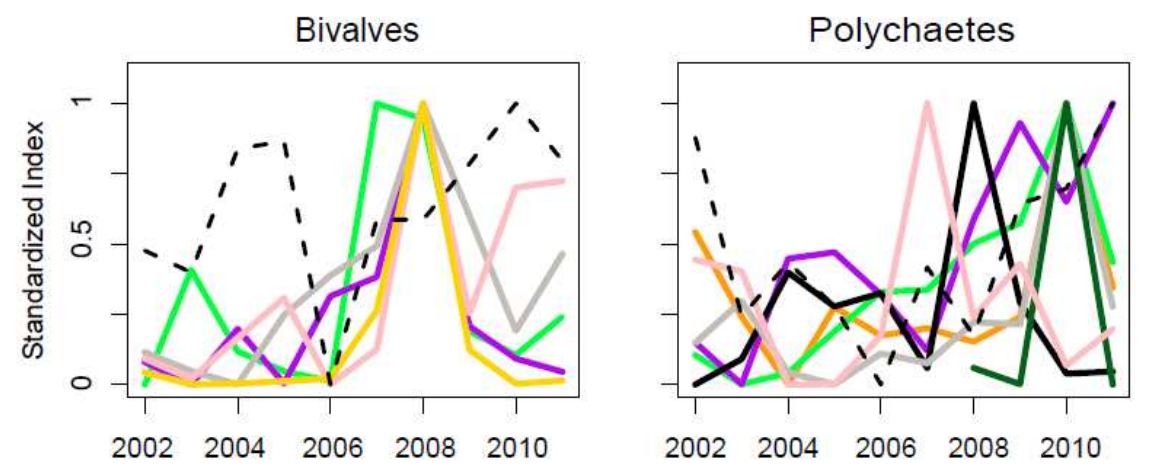

- Spotted hake

- Striped bass

- Sum. flounder

Weakfish

White perch

Prey Index

- As labeled

Fig. 7. Annual indices of prey consumption derived from the delta generalized additive mixed-effects models. Consumption of each prey by a predator was standardized to range from 0-1 (solid, colored lines). Standardized prey abundance index denoted with dashed line, but not available for mysids. 